\title{
Habitat heterogeneity reduces homogenisation impacts of a non-native water plant
}

\author{
Jorge Salgado ${ }^{1}$, Carl Sayer ${ }^{2}$, Nigel Willby ${ }^{3}$, Ben Goldsmith ${ }^{2}$, Thomas Davidson ${ }^{4}$, Suzanne \\ McGowan ${ }^{5}$, Ambroise Baker ${ }^{6}$, Ian Patmore ${ }^{2}$, Patrick Bexell ${ }^{2}$, and Beth Okamura ${ }^{7}$ \\ ${ }^{1}$ University of Nottingham Faculty of Social Sciences \\ ${ }^{2}$ University College London \\ ${ }^{3}$ University of Stirling Faculty of Natural Sciences \\ ${ }^{4}$ Aarhus Universitet \\ ${ }^{5}$ University of Nottingham \\ ${ }^{6}$ Teesside University \\ ${ }^{7}$ Natural History Museum
}

November 2, 2020

\begin{abstract}
Successful plant invasions are hypothesised to be associated with close environmental matching or species poor communities. However, positive correlations between non-native abundance and native plant richness can also arise due to habitat heterogeneity (defined here as variation in abiotic and biotic conditions over space and time). We analysed survey and palaeoecological data for macrophytes in lakes covering a gradient of eutrophication and connectivity to partition the roles of environmental matching, macrophyte diversity and habitat heterogeneity in explaining abundance and invasibility of Elodea canadensis, a widely distributed non-native macrophyte in Europe. There was no association between invasibility and macrophyte species richness. Instead habitat heterogeneity variously enabled the coexistence of native macrophytes and E. canadensis in lake metacommunities over time. Invasion resistance was associated with high native macrophyte cover and unfavourable environmental conditions. We show how spatial and temporal scales can determine the relationship between habitat heterogeneity and invasibility in lake systems.
\end{abstract}

\section{Habitat heterogeneity reduces homogenisation impacts of a non-native water plant}

\section{Running title: invasions in heterogeneous lake landscapes}

Jorge Salgado ${ }^{1,2,3,4,}$ (Jorge.SalgadoBonnet@nottingham.ac.uk), CarlＤ. Sayer ${ }^{2} \quad$ (c.sayer@ucl.ac.uk), Nigel Willby ${ }^{8}$ (n.j.willby@stir.ac.uk), Ben Goldsmith ${ }^{2}$ (b.goldsmith@ucl.ac.uk), Thomas A. Davidson ${ }^{5}$ (thd@bios.au.dk), Suzanne McGowan ${ }^{3} \quad$ (Suzanne.Mcgowan@nottingham.ac.uk), Ambroise G. Baker $^{2,6,7}$ (a.baker@tees.ac.uk), Patrik Bexell ${ }^{2}$ (potrik.potrik@googlemail.com), Ian R. Patmore ${ }^{2}$ (i.patmore@ucl.ac.uk), Beth Okamura ${ }^{1}$ (b.okamura@nhm.ac.uk).

${ }^{1}$ Department of Life Sciences, Natural History Museum, London, UK

${ }^{2}$ Environmental Change Research Centre, Department of Geography, University College London, London, UK

${ }^{3}$ School of Geography, University of Nottingham, Nottingham, UK

${ }^{4}$ Facultad de Ingeniería, Universidad Católica de Colombia, Bogota, Colombia 
${ }^{5}$ Lake Group and Arctic Research Centre, Department of Bioscience, Silkeborg, Aarhus University, Aarhus, Denmark

${ }^{6}$ School of Health and Life Science, Teesside University, Middlesbrough, UK

${ }^{7}$ National Horizons Centre, Teesside University, Darlington, UK.

${ }^{8}$ Biological and Environmental Sciences, University of Stirling, Stirling, UK

Key words : beta diversity, boosted regression trees, connectivity, Elodea canadensis, invasive species, metacommunities, plant cover, shallow lakes, species richness, species abundance

Type of article : Letters

Number of words in Abstract (150), Number of words in text (4994), number of references (58); number of figures (6)

Corresponding author : Jorge Salgado (Jorge.SalgadoBonnet@nottingham.ac.uk)

Statement of authorship : JS conceived the ideas; JS, BG, TD, CS, IP, PB, and BO collected the contemporary and palaeo- data; JS analysed the data and wrote the first manuscript; BO, CS, AB, NW, TD, SM contributed essentially to the interpretation and wording of the final version.

Data accessibility statement : should the manuscript be accepted, the data supporting the results will be archived in an appropriate public repository (Dryad, Figshare or Hal) and the data DOI will be included at the end of the article.

Abstract

Successful plant invasions are hypothesised to be associated with close environmental matching or species poor communities. However, positive correlations between non-native abundance and native plant richness can also arise due to habitat heterogeneity (defined here as variation in abiotic and biotic conditions over space and time). We analysed survey and palaeoecological data for macrophytes in lakes covering a gradient of eutrophication and connectivity to partition the roles of environmental matching, macrophyte diversity and habitat heterogeneity in explaining abundance and invasibility of Elodea canadensis, a widely distributed non-native macrophyte in Europe. There was no association between invasibility and macrophyte species richness. Instead habitat heterogeneity variously enabled the coexistence of native macrophytes and E. canadensis in lake metacommunities over time. Invasion resistance was associated with high native macrophyte cover and unfavourable environmental conditions. We show how spatial and temporal scales can determine the relationship between habitat heterogeneity and invasibility in lake systems.

\section{INTRODUCTION}

The ability of a non-native plant species to invade depends on resource availability, natural enemies and the physical environment (Shea \& Chesson 2002). Accordingly, three hypotheses have been proposed to explain invasion success (Jeschke 2014): (1) The diversity-invasibility hypothesis (Elton 1958; Kennedy et al. 2002; Levine et al. 2004) posits that species- and functionally-rich communities limit establishment opportunities for invaders by reducing access to resources; (2) The environmental-matching hypothesis (Mack et al. 2000; Shwartz et al. 2009) postulates that, irrespective of local native biota, plant species will have higher invasion success if introduced to environments similar to those in their natural optimal range; (3) The invasion paradox (Levine \& D'Antonio 1999; Fridley et al. 2007) proposes that invasive species spread over time through native metacommunities (communities linked by dispersal) in a heterogeneous landscape, leading to the regional coexistence of both native and non-native plant species. We subsequently refer to these as invasion hypotheses 1, 2 and 3, respectively.

Processes affecting biotic interactions and species distributions are scale-dependent (McGill 2010). At the landscape scale, both habitat quality and heterogeneity (defined here as the spatial and temporal variation in biotic and abiotic conditions) within and between lakes may facilitate species coexistence, regardless of their 
native status (Shea \& Chesson 2002; Davies et al. 2005). Habitat heterogeneity therefore has the potential to concurrently increase invasion probability whilst reducing invasion impact by promoting coexistence in space and time that might be precluded in a more homogenous setting (Melbourne et al. 2007; Clark et al. 2013). Thus, biological assemblages in a given landscape may include species that are extirpated at some sites but present at others through spatial and/or temporal storage effects, provided there is sufficient regional connectivity and spatiotemporal habitat heterogeneity (Melbourne et al. 2007).

In lake landscapes, macrophyte species distributions may be determined by the hydrological network (Salgado et al. 2018a). For example, communities in hydrologically-connected lakes may be particularly influenced by repeated colonisation events; i.e. mass effects (Capers et al. 2010) while local environmental factors may dictate community structure through species sorting according to habitat optima in more isolated lakes (Salgado et al. 2019). Habitat heterogeneity may therefore be spatially autocorrelated with hydrological connectivity. Although, there have been attempts to quantify how spatial autocorrelation affects invasibility dynamics (e.g. Davies et al. 2005), disentangling the simultaneous effects of abiotic factors, biodiversity and spatially-structured dynamics on invasion processes in nature has proved challenging (von Holle 2013; Nunez-Mir et al. 2017). There is evidence that temporal variation in environmental stress factors and dispersal-related mechanisms may promote the co-existence of both native and non-native species in lake landscapes (Clark et al. 2013), and that this may explain a positive correlation between native diversity and exotic macrophyte abundance at any one time (Capers et al. 2007). Systems comprising multiple sites that span environmental gradients offer the possibility of more explicitly quantifying how spatial autocorrelation affects invasibility dynamics and hence scope to disentangle factors that contribute to regional coexistence.

Canadian pondweed (Elodea canadensis ) is considered amongst the most widespread non-native plant species in Europe (Hussner 2012; Nentwig et al. 2018). It was first recorded in Great Britain in 1836 (Simpson 1984). Thereafter it spread rapidly, reaching the maximum extent of its distribution in Great Britain and Ireland by the middle of the twentieth century (Simpson 1984). The rapid colonization and spread of this species is commonly attributed to a high capacity for vegetative propagation (Barrat-Segretain 1996) and tolerance of a broad range of physical-chemical conditions, including low illumination, enabling growth at a wide range of water depths and under eutrophication-induced shade (Abernethy et al. 1996; Zehnsdorf et al. 2015). Once established E. canadensis can quickly replace native submerged macrophytes by forming a dense, closed canopy (Howard-Williams et al. 1987; de Winton \& Clayton 1996; Zehnsdorf et al. 2015). Indeed, the propensity for encountering $E$. canadensis in eutrophic isolated temperate lakes has promoted the view that its spread and colonisation across Britain and Ireland is attributable to environmental-matching; i.e. hypothesis 2 above (O'Hare et al. 2012). However, few studies have investigated the patterns of spread of $E$. canadensisover space and time [in a multivariate environmental context].

Here we examine the drivers of E. canadensis abundance in space and time by focusing on the macrophyterich (> 40 submerged and floating-leaved water plant species), and environmentally-heterogeneous lowland shallow lake complex of the Upper Lough Erne (ULE) system in Northern Ireland. Present-day and historical data derived from surveys and sediment core analyses enable us to address the following questions:

To what extent do diversity-related factors (invasion hypothesis 1 ), abiotic factors (invasion hypothesis 2 ) and a regional gradient in lake habitat quality (invasion hypothesis 3 ) contribute to variation in $E$. canadensis abundance?

Does habitat heterogeneity (including spatial autocorrelation)per se promote both E. canadensis invasibility and coexistence with native macrophyte communities in space and time (decades-centuries)?

Answering these questions provides novel demonstration that both habitat heterogeneity and habitat quality influence the coexistence of native and non-native plants at landscape scales. We also provide evidence that invasion resistance is linked to stressful environments and when high native plant cover limits opportunities for E. canadensis to proliferate.

\section{METHODS}




\section{Site description}

The ULE system offers a natural template for understanding the effect of habitat heterogeneity on the spread of E. canadensis (i.e. testing invasion hypothesis 3 ), being composed of a large (surface area 3450 ha), generally shallow (mean water depth $2.3 \mathrm{~m}$ ) central lake (ULE), fed by the River Erne, which is linked by winter floods and various channels and tributaries, to a network of over 50 small $(<40$ ha), shallow $(<5 \mathrm{~m})$ satellite lakes (loughs; Fig. 1). The system has been subjected to eutrophication since the 1950s (Battarbee 1986; Zhou 2000) with current annual concentrations of total phosphorus (TP) and total nitrogen $(\mathrm{TN})$ ranging between $29-383 \mu \mathrm{g} / \mathrm{L}$ and $0.22-2.25 \mathrm{mg} / \mathrm{L}$ respectively. E. canadensis is thought to have colonized the ULE system in the 1880s (Simpson 1984). Records from the Botanical Society of Britain and Ireland (BSBI) and more recent macrophyte monitoring programmes indicate presence of E. canadensis in ULE and its satellite lakes from the 1950s (Table S1). The zebra mussel (Dreissena polymorpha) also invaded this system in the 1990s, resulting in strong phytoplankton biomass reductions and increases in water transparency in the ULE (Minchin et al. 2003).

Macrophyte sampling and diversity predictors

Macrophytes were sampled in four basins within the central ULE and in 13 satellite lakes representing a gradient of nutrient-enrichment, zebra mussel occurrence and hydrological connectivity to the ULE (Fig. 1). The lakes were grouped into three categories according to Salgado et al. (2019) as: Group 1 included the ULE and lakes directly connected to it through the River Erne (Castle, and Derrykerrib) or via tributaries (Doo and Mill). These lakes are diverse (macrophyte richness $=17.4 \pm 2.7)$, meso-eutrophic $(\mathrm{TP}=55.1 \pm 11.3$ $\mu \mathrm{g} / \mathrm{L}$ ), and have clear waters (secchi depth $=222 \pm 47 \mathrm{~cm}$ ) and high occurrence of zebra mussels. Group 2 lakes are connected to ULE by flows through intermediate lakes and associated tributaries (Killymackan, Cornabrass and Kilturk). The lakes are diverse (macrophyte richness $=18.7 \pm 4.6)$, eutrophic $(\mathrm{TP}=136$ $\pm 54.4 \mu \mathrm{g} / \mathrm{L}$; secchi depth=182.3 $\pm 55 \mathrm{~cm}$ ) and zebra mussels occur sparsely. Group 3 lakes (Head, Digh, Derryhowlaght and Gole) are more isolated than Group 2 lakes due to intervening small hills, woodlands and roads (Figure 1). These lakes are the least diverse (macrophyte richness $=9 \pm 3.5$ ) and most eutrophic $(\mathrm{TP}=176.8 \pm 89.3 \mu \mathrm{g} / \mathrm{L})$ and turbid (secchi depth=113.3 \pm 79.3 ; zebra mussels rarely occur $).$

Sampling was undertaken in $1 \mathrm{~m}^{2}$ units, approximating to the plant neighbourhood scale (i.e. where individual native plants may compete with $E$. canadensis ). The lake volume infested by macrophytes (PVI) method of Canfield \& Jones (1984) was used to characterize the distributions and abundances of native macrophytes (including charophytes, bryophytes and vascular plants) and of E. canadensis . Macrophytes were surveyed during the summers of 2008-09 at individual points from a boat by zig-zagging across the entire lake using grapnel sampling and visual observations with a bathyscope. At each sampling point we recorded latitude/longitude, water depth, average plant height, and species cover (\%). PVI was calculated at each point as: (macrophyte cover $x$ average height of macrophyte)/water depth. For comparisons with previous monitoring data (Table S1) and to assess E. canadensis abundance patterns at the lake scale, percentage of occurrence of $E$. canadensis at each lake was also calculated by dividing the number of sampling points at which E. canadensis was observed by the total number of sampling points within the lake X 100 .

The number of macrophyte sampling points varied according to lake size. A minimum of 30 points was sampled for the smaller ( $<10$ ha) lakes (Loughs Doo, Gole, Digh, Gole and Derryhowlaght) and between 6080 points for the remaining larger (12-30 ha) satellite lakes (Fig 1). The ULE was sampled across four separate lake zones ( $\sim 30 \mathrm{ha})$ : Crom State (54.161731, -7.436668), Lisnaskea Rd.-Trannish (54.225036, -7.475074), Derrylea Rd.-Trannish (54.218312, -7.469581), and Smith Strands-Trannish (54.204659, -7.480395). A total of 20 sampling points per ULE zone were surveyed and a total of 540 sampling points across all the study lakes were covered. While our sampling approach missed some macrophyte species known to occur in individual lakes, it nevertheless provides a useful representation of variation in macrophyte distributions and abundances for the majority of species at the plant neighbourhood scale (Salgado et al. 2018b).

Abiotic data

Our previous studies of the ULE system demonstrate that macrophyte communities are structured by lake 
water transparency, which is negatively related to nutrient concentrations (TP and TN) and positively correlated with zebra mussel occurrence (Salgado et al. 2018a, Salgado et al. 2019). Accordingly, we used water clarity as a predictor of environmental stress variation across the macrophyte sampling points. An index of water clarity for each sampling point was defined as: lake secchi depth measured at the deepest point of each lake/water depth at the sampling point.

Plant macrofossil data

Previously published plant macrofossil abundance data derived from dated sediment cores were used to represent macrophyte community changes over the last c. 120 years (Salgado et al. 2018a,b; Salgado et al. 2019a). Cores were taken from Castle Lough and the Trannish area of ULE (lake Group 1 ), from Cornabrass and Killymackan (Group 2), and from Gole and Head (Group 3 ). The plant-macrofossil data are available from the Dryad Digital Repository:https://doi.org/10.5061/dryad.3jj548d.

E. canadensis remains preserve poorly in lake sediments (Davies 1985) and so we inferred its temporal abundance from a recent macrophyte study in the ULE system (Salgado et al. 2019) and from available historical monitoring data (Table S1). Salgado et al. (2019) showed that macrophyte assemblages now found in the ULE or closely-connected lakes (e.g. Castle and Derrykerrib) are similar to those characterised in sediment cores prior to eutrophication (i.e. pre 1950s). However, macrophytes currently found in the more isolated eutrophic sites (e.g. Gole and Head) resembled those characteristics of sediment cores post eutrophication (i.e. post-1960). Accordingly, we used the current E. canadensis occurrence data in lakes close to the ULE as a surrogate of E. canadensis abundances prior to 1950 and the E. canadensis occurrence data for the isolated lakes to infer E. canadensis abundances during the onset of eutrophication from 1960-1980. More recent (post-1980) E. canadensis abundance data were obtained from macrophyte surveys conducted in 1988, 2006 and 2009 (Table S1). To standardise these various sources of E. canadensis occurrence into a single comparable abundance measurement, we assigned the data to the following abundance categories: 5 (100\%-80\% occupancy of sampled points); 4 (79\%-60\%); $3(59 \%-40 \%) ; 2(39 \%-20 \%) ; 1(19 \%-1 \%) ; 0(0 \%)$.

Statistical analysis

Diversity predictors

Two macrophyte measures were previously shown to influence susceptibility to invasion (Capers et al. 2007): diversity andplant cover. We therefore developed three complementary indicators from the macrophyte PVI data to estimate macrophyte diversity: native species richness, the Shannon-Wiener diversity index (henceforth referred to as native Shannon diversity) and native macrophyte beta diversity. These indicators address key elements of native macrophyte community structure: the number of species in a lake (richness), their relative abundances within a lake (Shannon diversity), and their compositional variation across space and time (beta diversity). The native macrophyte cover data (\%) collected during the PVI assessments at each sampling point were assigned to native plant cover (total sum of native macrophyte species cover) and to two functional growth forms (submerged plant cover or floating plant cover). Beta diversity was calculated as the compositional variation in the native macrophyte species' PVI values (excluding E. canadensis ) across all sampling points as estimated via principal curves analysis (PC; De'ath 1999). PC analyses were run using the prcurvefunction in the "analogue" package in R (Simpson et al. 2020), using Canonical Analysis as the starting point on square-root transformed PVI data. The plant macrofossil data were similarly grouped into five native diversity predictors: taxon richness, Shannon diversity, native plant cover, submerged plant cover and floating plant cover.

Diversity-invasibility in space and time

The relationship between native species richness and E. canadensis variation in space and time (hypothesis 1 ) was assessed using Pearson correlation coefficients. Correlations were assessed at both within- and among-lake scales for the contemporary data and at the within-lake scale for the palaeo-data. Since unvegetated sampling points could produce spurious positive correlations between $E$. canadensis abundance and native macrophytes at the within lake scale (Capers et al. 2007), we removed these from all analyses. Sampling points with native 
macrophytes but no E. canadensis or with onlyE. canadensis were retained. Negative correlations between $E$. canadensis abundance and speciose native assemblages would be supportive of hypothesis 1 (Beaury et al. 2019). Positive correlations would support hypotheses 2 and 3 by suggesting that coexistence of native and invasive species in space and time is mediated by habitat heterogeneity (Clark et al. 2013).

Role of diversity and abiotic factors

In an attempt to control extrinsic anthropogenic variables that affect native and non-native plant richness, as a second complementary analytical step, we used a combination of Boosted Regression Tree analysis (BRT; Elith et al. 2008) and Random Forest Analysis (RFA; Breiman 2001). These two analyses address more specifically the extent to which diversity and abiotic factors alone determine E. canadensis abundance variation (Feld et al. 2016a). BRT was used to partition the variation in E. canadensis abundance explained by diversity (hypothesis 1 ) and abiotic descriptors (hypothesis 2 ) alone, and how they might together reflect habitat heterogeneity (hypothesis 3 ) at the landscape scale (Feld et al. 2016b). BRT constitutes a machinelearning method that combines classical regression tree analysis with boosting (Elith et al. 2008). BRT was ideal for our study as it can accommodate collinear data (e.g. latitude and longitude) and handle linear and non-linear descriptors with missing values (Elith et al. 2008). BRT partitioning (pBRT) was assessed through an additive partial regression scheme following Feld et al. (2016b). This analysis decomposed each BRT-explained variation into four fractions: (i) pure diversity, (ii) pure abiotic, (iii) shared diversity/abiotic, and (iv) unexplained variation. The shared fraction (iii) represents the variation that may be attributed to biological and/or abiotic descriptors together and is obtained additively in partial regression.

To reduce any spatial autocorrelation in the data arising due to the underlying hydrological network and to evaluate whether the importance of diversity and abiotic predictors in explaining E. canadensisabundance shifted with degree of lake connectivity and eutrophication (hypothesis 3 ), we run independent pBRTs for each lake group using the "dismo" (Hijmans et al. 2017) and "gbm" (Greenwell et al. 2019) packages in R (R Core Team 2019). For each pBRT we used Gaussian distributions, tree complexity of 2, a learning rate of between 0.005 and 0.001 , and a bag fraction of 0.5 (Elith et al. 2008). Theset.seed (123) argument in R was used for each BRT as a numerical starting point. Between 145-250 observations per lake group were analysed for each pBRT in order to deliver stable and reliable results (Feld et al. 2016a).

RFAs were then used to assess the extent to which diversity predictors explain E. canadensis abundances through time. Similar to BRTs, RFA is suited to analysing non-linear relationships by fitting a number of models (regression trees) to bootstrapped data subsets with the advantage of handling datasets with a low number of observations and predictors; i.e. our palaeo-data (Elith et al. 2008). RFAs were run using the function rfsrc of the package "randomForestSRC" (Ishwaran \& ThenKogalur 2016).

\section{RESULTS}

With the exception of Gole Lough, E. canadensis was encountered in all study sites (Fig. 1). The highest mean percentage occurrence of E. canadensis per lake was in Group 1 lakes (48\%), followed by Group 2 lakes (32\%), and Group 3 lakes (28\%). Current native macrophyte species richness and E. canadensis sample occupancy were positively correlated among lakes $(\mathrm{r}=0.44 ; \mathrm{P}=0.08)$ (Fig 2a). This positive relationship became significantly stronger $(\mathrm{r}=0.74 ; \mathrm{P}<0.01)$ after excluding Kilturk Lake, which was identified as an outlier by having 19 native macrophytes species but an E. canadensis occupancy of just 9\% (Fig. 2a).

Positive correlations between current native macrophyte species richness and E. canadensis were similarly observed within lakes for two thirds of the sites (including all four basins in the ULE which were treated as a single lake) (Fig. 2). Positive correlations between lake taxon richness of plant macrofossils and E. canadensis abundances were observed over time for Castle, Cornabrass, Killymackan, Head and Gole Lakes (Fig. 5). No association between surveyed native macrophyte species richness and E. canadensis abundance was observed for the Lakes Killymackan, Derrysteaton, Derryhowlaght and Head.

pBRTs showed that the importance of the pure abiotic fraction in explaining E. canadensis abundance variation declined from $30 \%$ in Group 1 to $13 \%$ in Group 3 (Fig. 3). Within the pure abiotic fraction, 
latitude explained almost half of the variation (48\%) in Group 1, but just 9\% in Group 3 . Water clarity in Group 3 explained $68 \%$ of the abundance variation compared with only $24 \%$ in Group 1 (24\%). Longitude effects remained relatively constant across the three lake groups, explaining $24 \%$ of the abiotic fraction in Group 1, 21\% in Group 2, and 23\% in Group 3 .

The importance of the pure diversity fraction in explaining E. canadensis abundance variation in the pBRTs almost doubled from $17 \%$ in Group 1 to $31 \%$ in Groups 2 and 3 (Fig. 3). Native beta diversity emerged as the most important predictor, accounting for almost two thirds of the pure diversity fraction in Groups 1 and 2 ( $61 \%$ and $62 \%$ respectively), and $40 \%$ of the variation in Group 3 . The importance of native Shannon diversity showed an increasing trend from relatively low levels of explained variation in Group 1 (8\%) to nearly four fold higher (31\%) in Group 3. The explanatory importance of floating plant cover increased from Group 1 (10\%) to Group 3 (16\%), whilst overall plant cover was most influential in Group 1 (16\%) compared toGroup 2 (8\%) and Group 3 (7\%). The influence of submerged plant cover was generally low among the three groups, explaining just $5 \%-7 \%$ of the pure diversity fraction. The proportion of variance jointly attributable to the fraction of both abiotic and diversity descriptors increased from Group 1 (37\%) to Group 3 (51\%). The proportion of unexplained variation declined from $16 \%$ in Group 1 to $5 \%$ in Group 3 .

The pBRT fitted function plots (Figure 4) show that E. canadensisabundance variation was spatially related to latitude and longitude sampling points. There were also marked reductions in E. canadensis abundances with declining water clarity (index values $<1.2)$ and with increases in native plant cover $(>60 \%)$, in particular for Groups 2 and 3. A nonlinear pattern with three distinct phases of $E$. canadensis abundances and native macrophyte beta diversity also emerged, characterised by: i) abundant E. canadensis co-occurring with diverse native macrophyte communities and high submerged plant cover; ii) low abundances or absences of $E$. canadensis coupled with high native plant cover and low native macrophyte diversity; and iii) abundant $E$. canadensis co-occurring with diverse native macrophyte communities and high floating plant cover.

RFA on the palaeo-data in Group 1 lakes identified beta diversity as the most important predictor in explaining E. canadensisabundance variation through time (Fig. 6a). Shannon diversity and floating plant cover were also influential. E. canadensisabundances were positively related to all three diversity predictors. For Group 2, variation in submerged plant cover was the most important driver of $E$. canadensis abundances followed by beta diversity and Shannon diversity, respectively (Fig. 6b). Here, E. canadensis abundances were positively related to beta diversity and Shannon diversity values, whilst negatively related to submerged plant cover. The analysis of Group 3 lakes identified plant cover as the most important variable in explaining $E$. canadensis abundance variation through time (Fig. 6c). Beta diversity, submerged plant cover, and Shannon diversity also positively influenced $E$. canadensisabundances.

\section{DISCUSSION}

The extent to which diversity-related processes (diversity-invasibility hypothesis 1 ), abiotic factors (environmental-matching hypothesis 2 ) and habitat heterogeneity (invasion paradox hypothesis 3 ) influence the spread of non-native aquatic macrophytes in space and time in European lakes has received little empirical attention. We use E. canadensis as a model system in which to address this general question using survey and palaeolimnology data to partial out the significance of different diversity signatures and abiotic predictors. This enabled us to test three competing hypotheses and to demonstrate that habitat heterogeneity has played a defining role in driving variation in E. canadensisabundance over space and time.

We found a nested spatial dependence between E. canadensisabundance and the location of sampling points in each lake (Fig. 4). This spatial structure in the data suggests that besides water clarity and depth there might be other unmeasured within-lake abiotic factors (e.g. surface area and basin morphology) that also influence E. canadensis abundance. The influence of this spatial structure in determining E. canadensis abundance diminished with lake isolation. Such a spatial pattern is in line with our previous studies of the ULE system showing that eutrophication has spread unevenly across the lakes (Salgado et al. 2018a; Salgado et al. 2019). In particular, native macrophyte assemblages in the more eutrophic and isolated lakes 
of Group 3 have become more homogenous over time, unlike those lakes with a higher degree of connectivity to the central lake (Salgado et al. 2018a). Macrophyte assemblages undergoing such homogenisation may have reduced effects on E. canadensisabundance arising from any unique lake properties.

After accounting for spatial autocorrelation in the data we found that variation in water clarity and diversity measures among the lakes together explained other significant portions of variation in E. canadensis abundance. In lakes with greater hydrological connectivity (Groups 1 and 2), E. canadensis abundances were less influenced by water clarity than by beta diversity. This pattern may be explained by higher prevalence of zebra mussels in these more connected lakes (and consequently improved water clarity; Salgado et al. 2019a), and source sink dynamics that maintain heterogeneous plant associations at the local scale (Salgado et al. 2018a,b). In contrast, E. canadensis abundances in more isolated headwaters (Group 3 ) were strongly impacted by low water clarity, floating plant cover and native Shannon diversity (mostly driven by Digh Lough). These drivers are consistent with biotic homogenisation in these more degraded lakes where species-sorting processes previously dominated (Salgado et al. 2018a).

Much of the variation in E. canadensis abundance over space and time was related to the interplay of beta diversity and plant cover. These two native plant community attributes have been found to better capture macrophyte ecological change dynamics in other human-dominated landscapes than species richness alone (Capers et al. 2007; Fu et al. 2019). The consistently positive correlation between E. canadensis abundance and native species richness in each lake over space and time suggests that in the ULE system, native species richness does not confer invasibility resistance. Instead, it suggests that native and non-native species respond similarly to within-lake and regional habitat heterogeneity. This overwhelms any negative effects of local diversity on E. canadensis, thus native and non-native species coexist across the landscape (Levine 2000; Jiang \& Morin 2004; Davis et al. 2005). Although causal relationships are difficult to discern from our observational data, we propose that locations favourable for native macrophytes, may generally therefore also favourE. canadensis (Melbourne et al. 2007).

While the presence of diverse native macrophyte species increased the probability of occurrence of $E$. $c a$ nadensis within the lakes, relationships with macrophyte beta diversity and plant cover suggest that $E$. canadensis abundance is be limited by high plant cover. This pattern was also revealed through time for lake Groups 1 and2 and in regional-scale plant invasion studies (Cleland et al. 2004; Capers et al. 2007; Davies et al. 2007). The positive association between plant cover and E. canadensisthrough time in Group 3 lakes, likely reflects the overall responses of macrophyte communities in these lakes to more advanced eutrophication. Different processes may therefore control the establishment vs. proliferation of E. canadensis . For example, spatial and temporal environmental heterogeneity may facilitate establishment and coexistence by providing a range of opportunities forE. canadensis to invade (Davis et al. 2005; Clark et al. 2013). However, high native plant cover could lower resource availability for a non-native colonist, thereby reducing opportunities to proliferate (Cleland et al. 2004; Davis et al. 2007).

Overall, our data support hypotheses 3. Despite observingE. canadensis in all but one site, abundances in lakes were generally low to moderate. This finding, coupled with a positive relationship between E. canadensis and speciose communities over space and time, indicate sufficient environmental heterogeneity within and among-lakes to enable coexistence of native and non-native macrophytes (Clark et al. 2013) and hence, reduced the often described macrophyte homogenisation impacts of non-native species (Muthukrishnan \& Larkin 2020). Habitat heterogeneity was also related to macrophyte beta diversity and plant cover variation.

Inferring the history of E. canadensis invasion

Palaeolimnological data reveal that at the time, that E. canadensis colonised the ULE system in the late 1800s, macrophyte communities were similar to those currently observed in Group 1 lakes (Salgado et al. 2019). Simpson (1984) reported a cycle of local colonization by E. canadensis involving establishment over a three-year period and a subsequent rapid increase in abundance. Given the extensive interconnection by winter flooding E. canadensisprobably spread rapidly to many sites. Following its widespread establishment, E. canadensis probably therefore persisted at moderate abundances for a long period, co-existing with a 
reported high diversity of other submerged species across the lakes (Salgado et al. 2018a). Subsequently, post-1950s, paleoecological data indicate gradual biotic changes associated with more eutrophic conditions that intensified after the 1980s (Battarbee 1986) but with differential local nutrient concentrations influencing biota (Salgado et al. 2019). These post-1950s biotic shifts involved gradual increases in floating plant cover and dominance of fine-leaved Potamogeton species (Fig. 5), although some sites, such as Castle Lough and Mill Lough, have maintained high macrophyte species diversities and abundances. Reductions in $E$. canadensis abundance in the most degraded lakes of Group 3 and negative associations with plant cover suggest a gradual decline in abundance across the ULE system over the last three to four decades leading to its current status of being widespread but seldom very abundant.

Reconstructing E. canadensis abundance over time based on survey and sediment core data may have limitations. For instance, some species may have been unrecorded and detection in sediment cores may be biased by preservation issues and under-representation of rare or distantly located macrophyte taxa (Zhao et al. 2006; Clarke et al. 2014). Our assessments of native macrophyte richness variation over space and time probably favour the more abundant taxa. Unique lake histories could have also introduced some discrepancies between the observed current $E$. canadensis occurrence and the inferred past abundance (Bennion et al. 2018). Nevertheless, analyses of both palaeo- and contemporary data showed a consistent positive relationship between $E$. canadensis abundance and native plant richness in most lakes. Plant cover, beta diversity, and Shannon diversity similarly emerged as the main predictors in explaining the temporal variation of $E$. canadensis abundance. These lines of evidence coupled with the history of Elodea spread in the British Isles (Simpson 1984) thus allow us to hypothesize what the general long-term patterns of E. canadensis spread in the ULE system would as described above.

Conclusions and perspectives

E. canadensis is commonly reported in the invasion literature to dominate over native submerged species once well established, and to exert strong negative ecosystem engineering effects (Rørslett et al. 1986; Schwarz et al. 2015). Conditions considered to favourE. canadensis include high availability of nutrients, suitable carbon sources, and silty substrates (Schwarz et al. 2015). Such conditions generally prevailed across our study sites (Salgado et al. 2019) and would support the environmental-matchinghypothesis 2. However, our data provide a novel demonstration that habitat heterogeneity enables the coexistence of native and non-native plant species at landscape scales. We also found evidence for invasion resistance in stressful environments or when native plant cover of native species is high.

Predicting future trajectories of E. canadensis distribution and abundance is challenging. E. canadensis has spread in the British Isles by asexual growth, from one giant male clone (Simpson 1984). It is therefore possible that conditions (e.g. disease) may eventually challenge the persistence of clonal populations. Furthermore, with globalization, unexpected and novel invasion dynamics are becoming ever likelier (Pysek et al. 2020). Meanwhile, like many other shallow lake systems, the ULE system is declining through advancing eutrophication, which, if unabated, will eventually override positive regional species storage effects (Salgado et al. 2018a). These impacts are likely to accelerate in forthcoming decades due to climate-driven magnification of eutrophication effects in lakes (Birk et al. 2020). In addition, the sibling invasive species, Elodea nuttallii, is rapidly spreading across the ULE system and outcompeting $E$. canadensisunder high nutrient-enrichment conditions (Kelly et al. 2015). Quantifying the dynamics of these two invasive species at both landscape and temporal scales is critical, therefore, if invasion processes are to be better understood.

\section{ACKNOWLEDGEMENTS}

We thank the Natural History Museum, London for supporting fieldwork as part of JS PhD. Further support for fieldwork was provided by a Hugh Cary Gilson Memorial Award from the Freshwater Biological Association. We thank the University of Nottingham and the UKRI-GCRF Living Deltas Hub for supporting JS as a postdoctoral researcher and Universidad Católica de Colombia for supporting JS research under Semillero de Investigacion HIDROIMPACTOS. We thank CIRCE under the AU ideas programme for supporting TD contribution. We thank the Lake BESS project (Natural Environment Research Council grant, NE/K015486/1 
for funding sediment dating and paleoecological analysis of the Gole lake core and for supporting AB. We thank NIEA for provision of water chemistry data for the central lake (Upper Lough Erne), many landowners for site access and hospitality, Charlotte Hall, Stephen Brooks and Peter Hammond for fieldwork assistance and Laura Petetti for provision of data from the ULET2 core and for fieldwork assistance.

\section{REFERENCES}

Abernethy, V.J., Sabbatini, M.R. \& Murphy, K.J. (1996). Response ofElodea canadensis Michx, and Myriophyllum spicatum L. to shade, cutting and competition in experimental culture.Hydrobiologia , 340 , 219-224.

Barrat-Segretain, M.H. (1996). Strategies of reproduction, dispersion, and competition in river plants: A review. Vegetatio ,123, 13-37.

Battarbee, R.W. (1986). The Eutrophication of Lough Erne Inferred from Changes in the Diatom Assemblages of ${ }^{210} \mathrm{~Pb}$-and ${ }^{137} \mathrm{Cs}-$ Dated Sediment Cores. Proc. R. Ir. Acad. C., 86B , 141-168.

Beaury, E.M., Finn, J.T., Corbin, J.D., Barr, V. \& Bradley, B.A. (2020). Biotic resistance to invasion is ubiquitous across ecosystems of the United States. Ecol. Lett. , 23, 476-482.

Bennion, H., Sayer, C.D., Clarke, S.J., Davidson, T.A., Rose, N.L., Goldsmith, B. et al. (2018). Sedimentary macrofossil records reveal ecological change in English lakes: Implications for conservation. J. Paleolimnol. , $60,329-348$.

Birk, S., Chapman, D., Carvalho, L., Spears, B.M., Andersen, H.E., Argillier, C. et al. (2020). Impacts of multiple stressors on freshwater biota across spatial scales and ecosystems. Nat. Ecol. Evol., https://doi.org/10.1038/s41559-020-1216-4

Breiman, L. (2001). Random forests. Mach. Learn ., 45 , 5-32.

Canfield, D.E. \& Jones, J.R. (1984). Assessing the trophic status of lakes with aquatic macrophytes. Lake Reservoir Manag. ,1 , 446-451.

Capers, R.S., Selsky, R., \& Bugbee, G.J. (2010). The relative importance of local conditions and regional processes in structuring aquatic plant communities. Freshw. Biol. , 55 , 952-966.

Capers, R.S., Selsky, R., Bugbee, G.J. \& White, J.C. (2007). Aquatic plant community invasibility and scale-dependent patterns in native and invasive species richness. Ecology , 88, 3135-3143.

Clark, G.F., Johnston, E.L. \& Leung, B. (2013). Intrinsic time dependence in the diversity-invasibility relationship. Ecology ,94, 25-31.

Clarke, G.H., Sayer, C.D., Turner, S., Salgado, J., Meis, S., Patmore, I. et al. (2014). Representation of aquatic vegetation change by plant macrofossils in a small and shallow freshwater lake. Veg. Hist. Archaeobot. , $23,265-276$.

Cleland, E.E., Smith, M.D., Andelman, S.J., Bowles, C., Carney, K.M., Claire Horner-Devine, M. et al. (2004). Invasion in space and time: Non-native species richness and relative abundance respond to interannual variation in productivity and diversity: Productivity, diversity and invasion. Ecol. Lett. , 7 , 947-957.

Davies, K.F., Harrison, S., Safford, H.D. \& Viers, J.H. (2007). Productivity alters the scale dependence of the diversity-invasibility relationship. Ecology , 88, 1940-1947.

Davies, K.F., Chesson, P., Harrison, S., Inouye, B.D., Melbourne, B.A. \& Rice, K.J. (2005). Spatial heterogeneity explains the scale dependence of the native-exotic diversity relationship. Ecology ,86 , 1602-1610.

Davis, F.W. (1985). Historical changes in submerged macrophyte communities of Upper Chesapeake Bay. Ecology , 66 , 981-993. 
de Winton, M.D. \& Clayton, J.S. (1996). The impact of invasive submerged weed species on seed banks in lake sediments. Aquat Bot., 53, 31-45.

De'ath, G. (1999). Principal curves: a new technique for indirect and direct gradient analysis. Ecology, 80 , 2237-2253.

Elith, J., Leathwick, J.R. \& Hastie, T. (2008). A working guide to boosted regression trees. J. Animal Ecol. , 77, 802-813.

Elton, C.S. (1958). The ecology of invasions by animals and plants . Methuen and Company, London, UK

Feld, C.K., Segurado, P. \& Gutiérrez-Cánovas, C. (2016a). Analysing the impact of multiple stressors in aquatic biomonitoring data: A 'cookbook' with applications in R. Sci. Total Environ., 573, 1320-1339.

Feld, C.K., Birk, S., Eme, D., Gerisch, M., Hering, D., Kernan, M.et al. (2016b). Disentangling the effects of land use and geo-climatic factors on diversity in European freshwater ecosystems.Ecol. Indic., 60 , 71-83.

Fridley, J.D., Stachowicz, J.J., Naeem, S., Sax, D.F., Seabloom, E.W., Smith M.D., et al . (2007). The invasion paradox: reconciling pattern and process in species invasions. Ecology , 88 , 3-17.

Fu, H., Yuan, G., Jeppesen, E., Ge, D., Li, W., Zou, D. et al.(2019). Local and regional drivers of turnover and nestedness components of species and functional beta diversity in lake macrophyte communities in China. Sci. Total Environ., 687, 206-217.

Greenwell, B., Boehmke, B., Cunningham, J., Developers, G.B.M. \& Greenwell, M.B. (2019). Package 'gbm'. R package version, 2 (5).

Hijmans, R.J., Phillips, S., Leathwick, J., Elith, J. \& Hijmans, M.R.J. (2017). Package 'dismo'. Circles , 9 , $1-68$.

Howard-Williams, C., Clayton, J.S., Coffey, B.T. \& Johnstone, I.M. (1987). Macrophyte invasions. In Inland Waters of New Zealand.(A.B. Viner). DSIR, Wellington, New Zealand, pp. 307-331.

Hussner, A. (2012). Alien aquatic plant species in European countries. Weed Res ., 52 , 297-306.

Ishwaran, H. \& Kogalur, U.B. (2016). Random Forests for Survival, Regression and Classification (RF-SRC). R Package Version 2.2.0.

Jeschke, J.M. (2014). General hypotheses in invasion ecology.Divers. Distrib. , 20 , 1229-1234.

Jiang, L. \& Morin, P.J. (2004). Productivity gradients cause positive diversity-invasibility relationships in microbial communities: Productivity gradients and community invasibility. Ecol. Lett. ,7 , 1047-1057.

Kelly, R., Harrod, C., Maggs, C.A. \& Reid, N. (2015). Effects ofElodea nuttallii on temperate freshwater plants, microalgae and invertebrates: Small differences between invaded and uninvaded areas. Biol. Invasions , 17, 2123-2138.

Kennedy, T.A., Naeem, S., Howe, K.M., Knops, J.M.H., Tilman, D. \& Reich, P. (2002). Biodiversity as a barrier to ecological invasion.Nature , 417, 636-638.

Levine, J.M., Adler, P.B. \& Yelenik, S.G. (2004). A meta-analysis of biotic resistance to exotic plant invasions: Biotic resistance to plant invasion. Ecol. Lett. , 7 , 975-989.

Levine, J.M. (2000). Species Diversity and Biological Invasions: Relating Local Process to Community Pattern. Science ,288, 852-854.

Levine, J.M. \& D’Antonio, C.M. (1999). Elton Revisited: A Review of Evidence Linking Diversity and Invasibility. Oikos , 87, 15-26.

Mack, R.N., Simberloff, D., Mark Lonsdale, W., Evans, H., Clout, M. \& Bazzaz, F.A. (2000). Biotic invasions: causes, epidemiology, global consequences, and control. Ecol. Appl. , 10 , 689-710. 
McGill, B.J. (2010). Matters of Scale. Science, 328, 575-576.

Melbourne, B.A., Cornell, H.V., Davies, K.F., Dugaw, C.J., Elmendorf, S., Freestone, A.L. et al. (2007). Invasion in a heterogeneous world: Resistance, coexistence or hostile takeover? Ecol. Lett. ,10 , 77-94.

Minchin, D., Maguire, C. \& Rosell, R. (2003). The zebra mussel (Dreissena polymorpha Pallas) invades Ireland: Human mediated vectors and the potential for rapid intranational dispersal. Proc. R. Ir. Acad. C, 103B , 23-30.

Muthukrishnan, R., \& Larkin, D.J. (2020). Invasive species and biotic homogenization in temperate aquatic plant communities. Glob. Ecol. Biogeogr ., 29 , 656-667.

Nentwig, W., Bacher, S., Kumschick, S., Pyšek, P. \& Vilà, M. (2018). More than "100 worst" alien species in Europe. Biol. Invasions ,20 , 1611-1621.

Nunez-Mir, G.C., Liebhold, A.M., Guo, Q., Brockerhoff, E.G., Jo, I., Ordonez, K. et al. (2017). Biotic resistance to exotic invasions: its role in forest ecosystems, confounding artifacts, and future directions. Biol. Invasions , $19,3287-3299$.

O'Hare, M.T., Gunn, I.D., Chapman, D.S., Dudley, B.J. \& Purse, B.V. (2012). Impacts of space, local environment and habitat connectivity on mac- rophyte communities in conservation lakes. Divers. Distrib. $, \mathbf{1 8}, 603-614$.

Pyšek, P., Hulme, P.E., Simberloff, D., Bacher, S., Blackburn, T.M., Carlton, J.T. et al. (2020). Scientists' warning on invasive alien species. Biol. Rev ., 000-000. doi: 10.1111/brv.12627.

Rørslett, B., Berge, D. \& Johansen, S.W. (1985). Mass invasion ofElodea canadensis in a mesotrophic, South Norwegian lake - impact on water quality: With 6 figures and 2 table in the text.SIL Proc., 1922-2010 , 22, 2920-2926.

Salgado, J., Sayer, C.D., Brooks, S.J., Davidson, T.A., Baker, A.G., Willby, N. et al. (2019). Connectivity and zebra mussel invasion offer short-term buffering of eutrophication impacts on floodplain lake landscape biodiversity. Divers. Distrib. , 25, 1334-1347.

Salgado, J., Sayer, C.D., Brooks, S.J., Davidson, T.A., Goldsmith, B., Patmore, I. et al. (2018a). Eutrophication homogenizes shallow lake macrophyte assemblages over space and time. Ecosphere ,9, e02406.

Salgado, J., Sayer, C.D., Brooks, S.J., Davidson, T.A. \& Okamura, B. (2018b). Eutrophication erodes interbasin variation in macrophytes and co-occurring invertebrates in a shallow lake: Combining ecology and palaeoecology. J. Paleolimnol. , $60,311-328$.

Shea, K. \& Chesson, P. (2002). Community ecology theory as a framework for biological invasions. Trends Ecol. Evol. , 17, 170-176.

Shwartz, A., Strubbe, D., Butler, C.J., Matthysen, E. \& Kark, S. (2009). The effect of enemy-release and climate conditions on invasive birds: A regional test using the rose-ringed parakeet (Psittacula krameri) as a case study. Divers. Distrib. , 15, 310-318.

Simpson, D.A. (1984). A short history of the introduction and spread ofElodea Michx in the British Isles. Watsonia , 15, 1-9.

Simpson, G.L., Oksanen, J., \& Simpson, M.G.L. (2020). Analogue. R Package

Spence, D.H.N. (1967). Factors controlling the distribution of freshwater macrophytes with particular reference to the Lochs of Scotland. J. Ecol. , 55 , 147-170.

Von Holle, B. (2013). Environmental stress alters native-nonnative relationships at the community scale. Biol. Invasions ,15 , 417-427 
Zehnsdorf, A., Hussner, A., Eismann, F., Ronicke, H. \& Melzer, A. (2015). Management options of invasive Elodea nuttallii andElodea canadensis . Limnologica , 51, 110-117.

Zhao, Y., Sayer, C.D., Birks, H.H., Hughes, M., \& Peglar, S.M. (2006). Spatial representation of aquatic vegetation by macrofossils and pollen in a small and shallow lake. J. Paleolimnol. , 35 , 335-350.

Zhou, Q. (2000). Long-term changes of nitrogen and phosphorus loadings to a large lake in North-West Ireland. Water Res. , 34, 922-926.

\section{FIGURES}

\section{Hosted file}

image1.emf available at https://authorea.com/users/372241/articles/490352-habitatheterogeneity-reduces-homogenisation-impacts-of-a-non-native-water-plant

Figure 1. Map of the Upper Lough Erne (ULE) system showing the geographical location of the system and the studied lakes (loughs) and the recorded abundances of Elodea canadensis during 2008-2009 (circles). The size of the circles represents an abundance scale of $0-5$, where 5 is maximum abundances and 0 (red circle) apparent absence. Superscripts numbers indicate the lake group that each lake belongs. The lake groups were selected according to the water flow direction:Group 1, lakes directly connected to the central lake (ULE) via the River Erne flow; Group 2, lakes with a direct lateral connection to the ULE; and Group 3 , lakes connected laterally to the ULE via one or more intermediate lakes. Water layers obtained from Ordnance Survey Northern Ireland https://www.nidirect.gov.uk/services/osni-online-map-shop and reproduced with the permission of Land \& Property Services (c) Crown Copyright 2018.

\section{Hosted file}

image2.emf available at https://authorea.com/users/372241/articles/490352-habitatheterogeneity-reduces-homogenisation-impacts-of-a-non-native-water-plant

Figure 2. The relationship between a) richness of survey native macrophyte species and Elodea canadensis lake percentage of occurrences at all the study lakes (Loughs). Kilturk Lough was identified (blue star) as an outlier and subsequently excluded in the second plot analysis. The relationship between richness of native macrophyte species and E. canadensis abundance at each lake sampling points in lake Group 1 (b); lake Group 2 (c) and (d) lake Group 3 . Pearson correlation coefficients, LOESS line trend and significance for ach analysis are indicated at each plot. ${ }^{*} \mathrm{p}<0.05 ;{ }^{* *} \mathrm{p}<0.01 ;{ }^{* * *} \mathrm{p}<0.001$.

\section{Hosted file}

image3.emf available at https://authorea.com/users/372241/articles/490352-habitatheterogeneity-reduces-homogenisation-impacts-of-a-non-native-water-plant

Figure 3. a ) Boosted Regression Trees (BRT) variance partitioning scheme on the three-study lake groups showing the pure and shared proportions of explained and unexplained variance in Elodea canadensis abundance patterns by abiotic metrics and macrophyte biodiversity metrics; b) Diversity fraction of the BRT variance partitioning analysis showing the unique contribution of five native macrophyte diversity metrics (Shannon diversity, plant cover, submerged plant cover, floating plant cover and beta diversity) on E. canadensis abundance variation across the three-study lake groups; c) Abiotic fraction of the BRT variance partitioning analysis showing the unique contribution of three abiotic metrics (water clarity, longitude and latitude) on E. canadensis abundance variation across the three-study lake groups. Only percentages values of explained variation $>10 \%$ are presented in the plots.

\section{Hosted file}

image4.emf available at https://authorea.com/users/372241/articles/490352-habitatheterogeneity-reduces-homogenisation-impacts-of-a-non-native-water-plant 
Figure 4. Smooth fitted functions plots between E. canadensis abundance variation and three abiotic metrics (water clarity, longitude and latitude) and five native macrophyte biodiversity metrics (Shannon diversity, plant cover, submerged plant cover, floating plant cover and beta diversity) obtained in the Boosted Regression Trees variance partitioning scheme analyses at each lake group. Water clarity values for each sampling point is defined as: lake secchi depth at the deepest point of each lake/water depth at the PVI sampling point. Plant cover, submerged plant cover, and floating plant cover values are expressed as \%.

\section{Hosted file}

image5.emf available at https://authorea.com/users/372241/articles/490352-habitatheterogeneity-reduces-homogenisation-impacts-of-a-non-native-water-plant

Figure 5. The temporal relationship between richness of native plant macrofossils and E. canadensis abundance at the within-lake scale in a) Castle Lough and the central Upper Lough Erne-ULE (Group 1 of lakes); b) Cornabrass Lough and Killymackan Lough (Group 2 ); and c) Gole Lough and Head Lough (Group 3 ). Pearson correlation coefficients and significance for each analysis are indicated on each plot. ${ }^{*} \mathrm{p}<0.05 ;{ }^{* *} \mathrm{p}<0.01 ;{ }^{* * *} \mathrm{p}<0.001$.

\section{Hosted file}

image6.emf available at https://authorea.com/users/372241/articles/490352-habitatheterogeneity-reduces-homogenisation-impacts-of-a-non-native-water-plant

Figure 6 . Results of Random Forest analysis showing the unique contribution of five native plant macrofossil diversity metrics (Shannon diversity, plant cover, submerged plant cover, floating plant cover and beta diversity) on E. canadensis abundance temporal variation across the three-study lake groups.

\section{SUPLEMNTARY MATERIAL}

\section{APPENDIX 1}

Table S1. Historical monitoring records of Elodea canadensis at 20 satellite lakes and the 4 basins in the central lake (ULE) in the ULE system at pre-1930; 1930-1949; 1950-1969; 1970-1986; 1988-1990, 2006-2007 and 2008-2009. Botanical records from the British Society \& Ireland (BSBI) Botanical are indicated by an $\mathrm{X}$; Abundance $=$ semi-quantitative scale of 0-5. Lakes showing a decline in Elodeaabundances over time are highlighted in bold.

\begin{tabular}{|c|c|c|c|c|c|}
\hline $\begin{array}{ll}\text { Lake } & \text { Pre- } 1930 \\
\text { (Lough) } & \end{array}$ & 1930- 1949 & 1950- 1969 & 1970- 1986 & 1988 & 2006 \\
\hline Abacon & & & $\mathrm{X}$ & 4 & 2 \\
\hline Castle & & & $\mathrm{X}$ & 3 & 4 \\
\hline Cornabrass & & & $\mathrm{X}$ & 3 & 4 \\
\hline Corracoash & & & $\mathrm{X}$ & 4 & 3 \\
\hline Corraharra* & & & $\mathrm{X}$ & 1 & 2 \\
\hline Derryhowlaght & & & $\mathrm{X}$ & 4 & 2 \\
\hline Derrykerrib & & & $\mathrm{X}$ & 4 & 4 \\
\hline Derrymacrow & & & $\mathrm{X}$ & 4 & 4 \\
\hline Derrysteaton & & & $\mathrm{X}$ & 4 & 3 \\
\hline Drumroosk & & & $\mathrm{X}$ & 5 & 1 \\
\hline Gole & & & $\mathrm{X}$ & 3 & 1 \\
\hline Killymackan & & & $\mathrm{X}$ & 4 & 4 \\
\hline Kilmore* & & & $\mathrm{X}$ & 1 & 1 \\
\hline Kilturk & & & $\mathrm{X}$ & 4 & 3 \\
\hline Digh & & & $\mathrm{X}$ & 2 & 2 \\
\hline Doo & & & $\mathrm{X}$ & 2 & 3 \\
\hline Head & & & $\mathrm{X}$ & 1 & 3 \\
\hline
\end{tabular}


Mill

Pound*

Sarah

Sessiagh

East

US904

ULE

Belleisle*

ULE

Crom*

ULE

Trannish*

ULE-FB

ULE-H

$\begin{array}{lll}\mathrm{X} & 4 & 4 \\ \mathrm{X} & 1 & 4 \\ \mathrm{X} & 3 & 3 \\ \mathrm{X} & 5 & 0 \\ \mathrm{X} & 5 & 2 \\ \mathrm{X} & 1 & 2 \\ \mathrm{X} & 1 & 3 \\ \mathrm{X} & & \\ & & \\ \mathrm{X} & & \\ \mathrm{X} & & \end{array}$

\section{3}

3

0

2

3

2

2

2

2

1

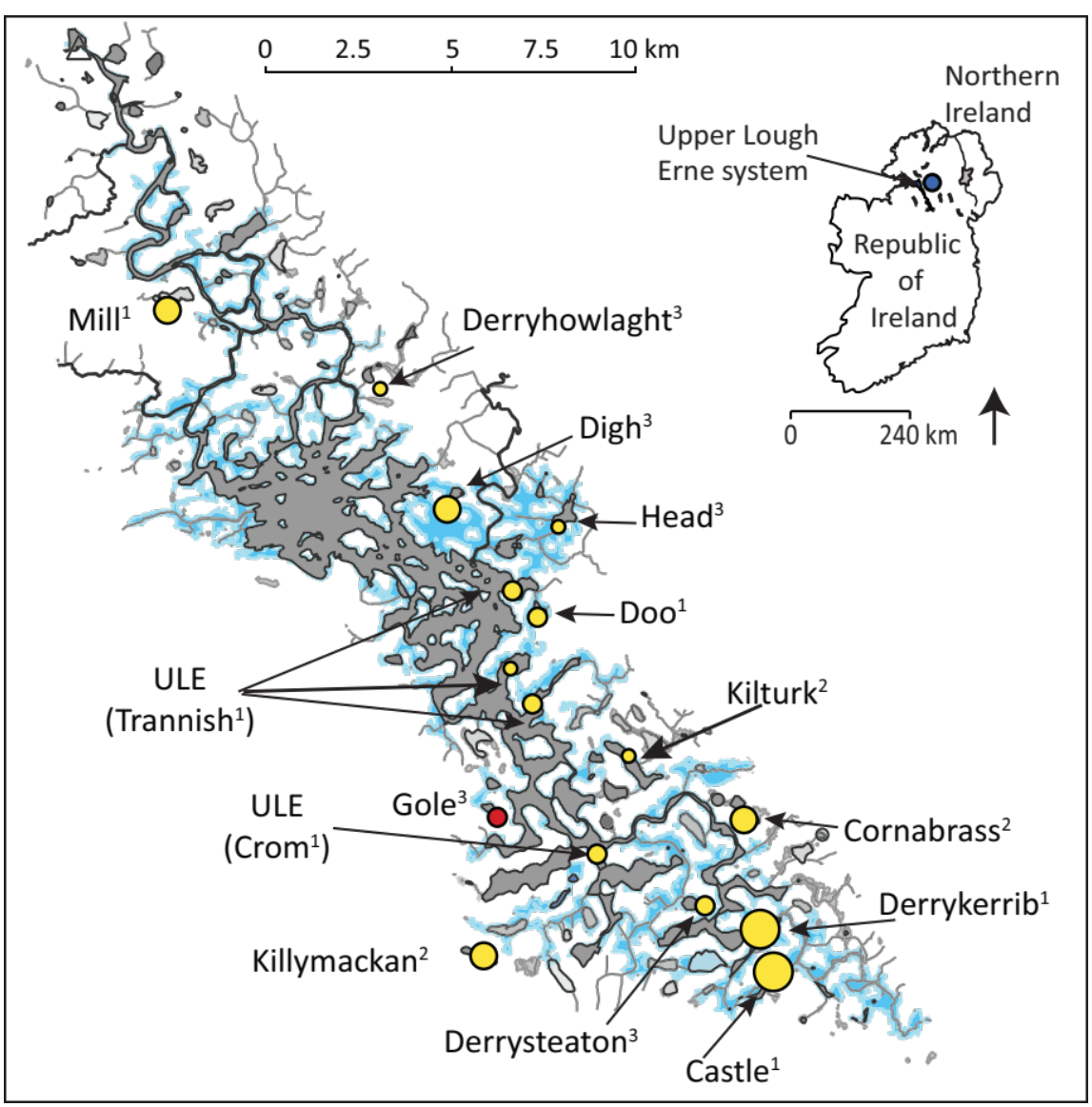



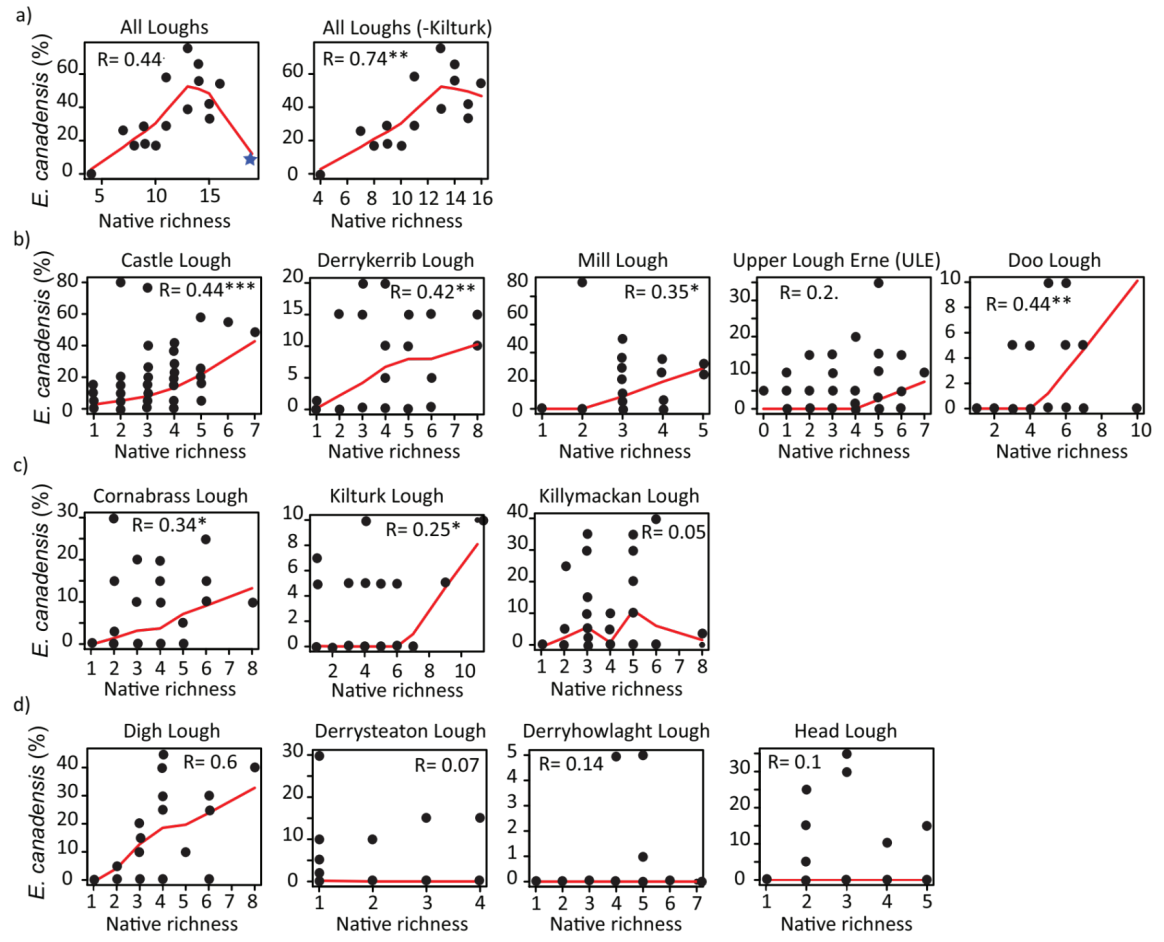

a)
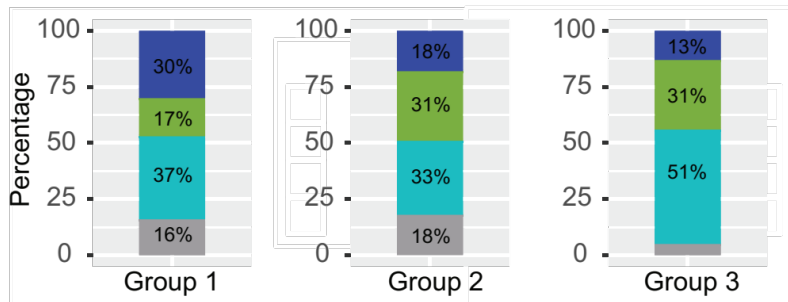

Abiotic Diversity

Shared

Unexplained
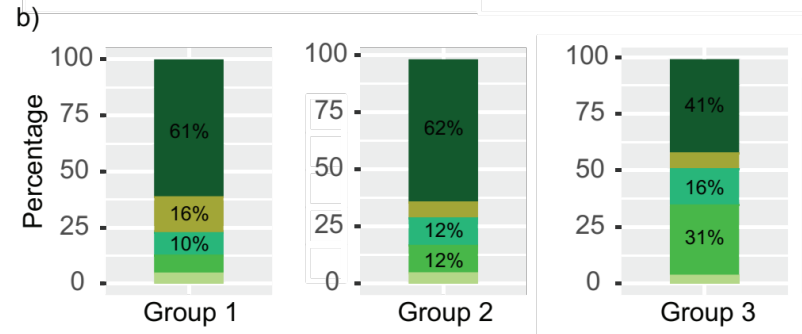

Beta diversity

Plant cover

Floating plant cover

Shannon diversiity

Submerged plant cover

c)
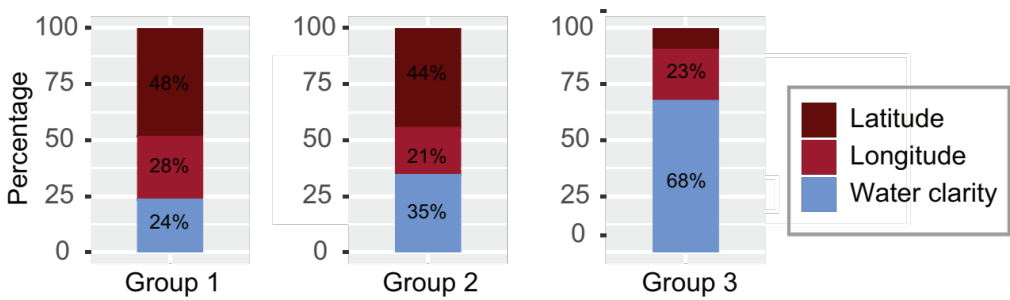
a) Group 1
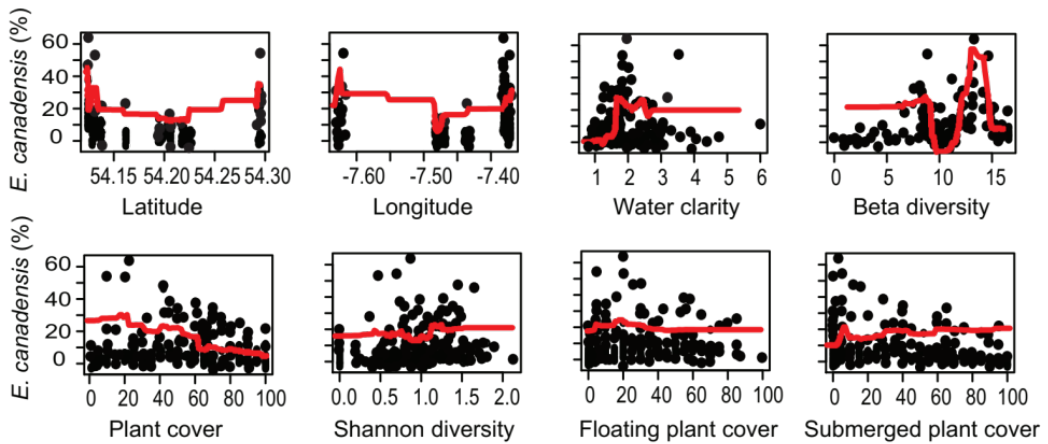

b) Group 2
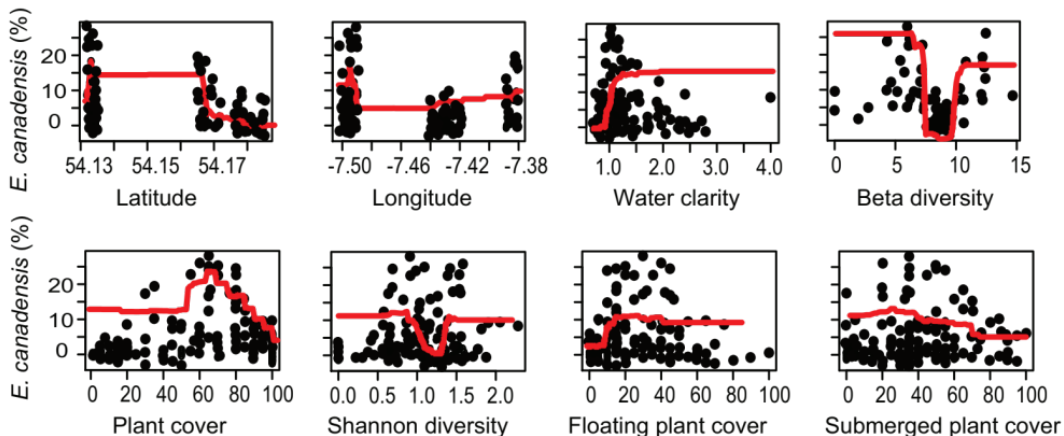

c) Group 3
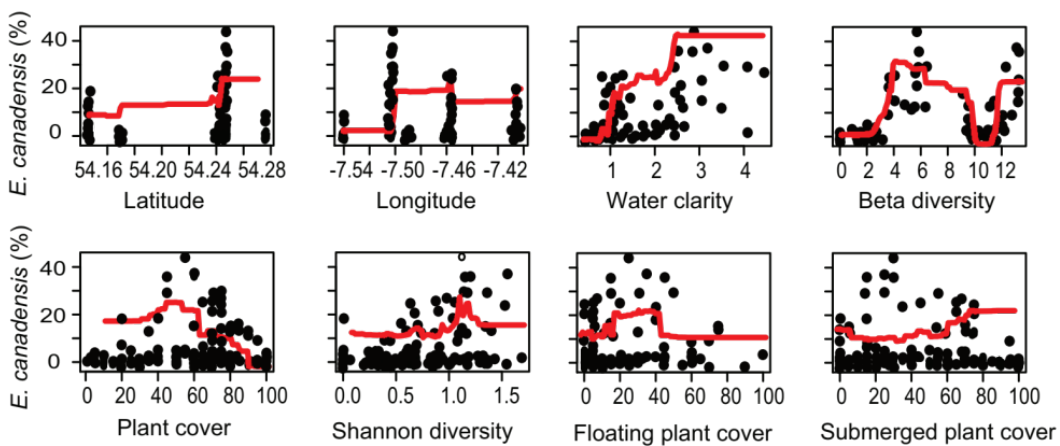

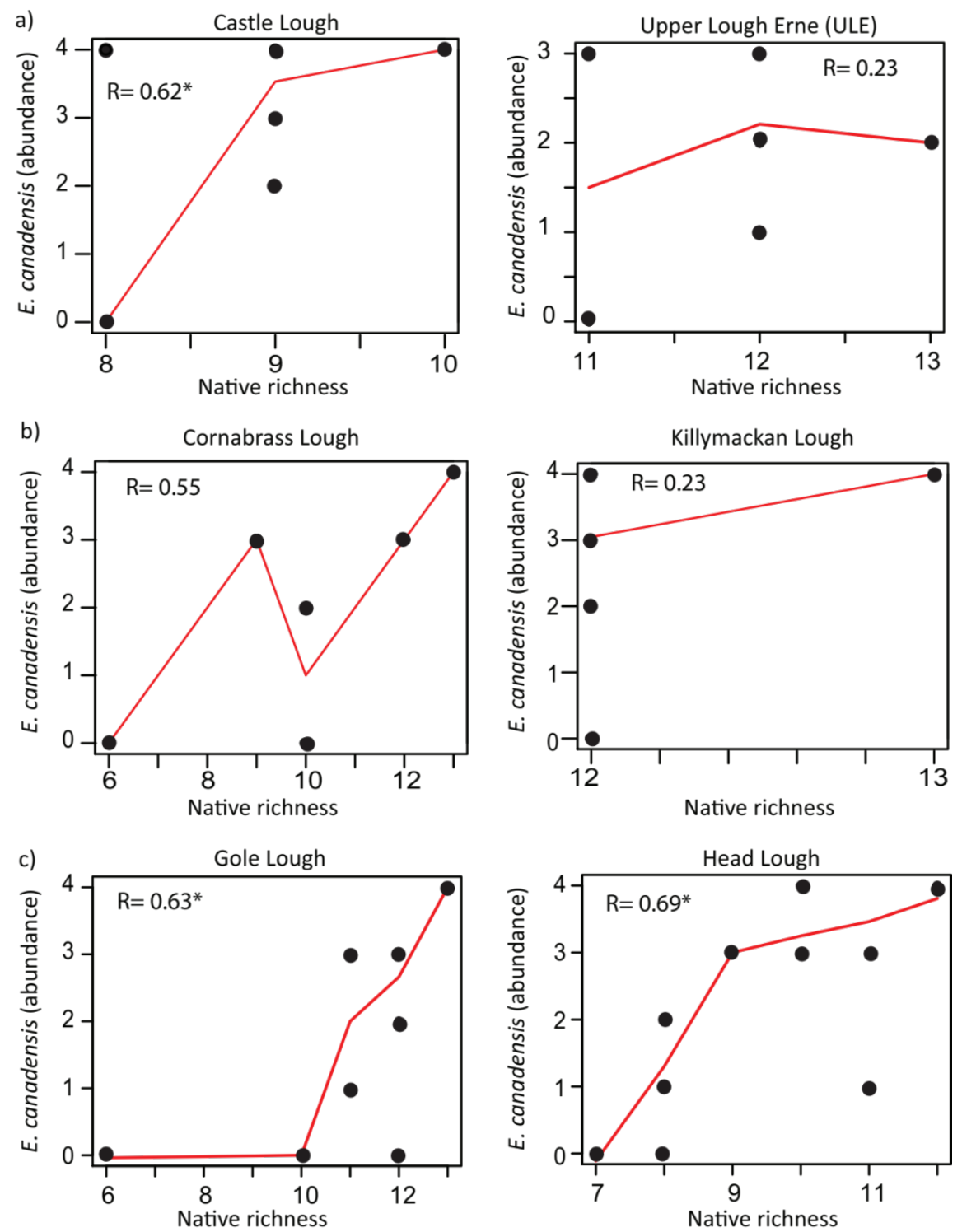


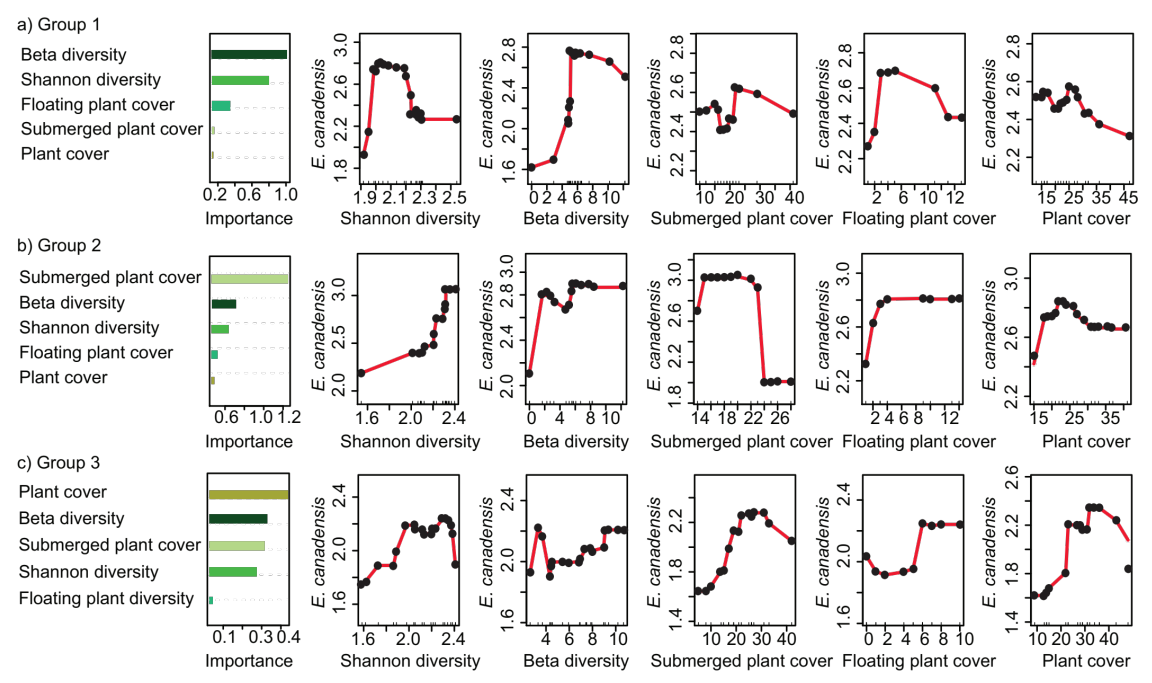

